\title{
Evidence of ubiquitous in vivo and in vitro expression of pro- apoptotic Smac/DIABLO protein in meningioma cell lines
}

\author{
CHRISTINA PFISTER ${ }^{1}$, RAINER RITZ ${ }^{1}$, ELIAS ENDEMANN ${ }^{1}$, JENS SCHITTENHELM ${ }^{2}$, \\ ANTJE BORNEMANN $^{2}$, MARCOS S. TATAGIBA ${ }^{1}$ and FLORIAN ROSER ${ }^{1}$ \\ ${ }^{1}$ Department of Neurosurgery, ${ }^{2}$ Institute of Brain Research, University of Tübingen, \\ Hoppe-Seyler-Str. 3, D-72076 Tübingen, Germany
}

Received December 17, 2008; Accepted February 18, 2009

DOI: $10.3892 /$ or_00000339

\begin{abstract}
Although meningiomas are one of the most common tumors in the central nervous system, the adjuvant treatment for recurrent or malignant meningiomas is not satisfactory. An intense interest in evaluating new molecular markers that may serve as potential therapeutic targets exists. Changes in apoptosis mechanisms play important roles in tumor pathogenesis. One pro-apoptotic protein is Smac/DIABLO, which neutralizes the inhibitors of apoptosis (IAPs). As Smac/ DIABLO has not been previously analyzed in meningiomas, We investigated the expression of Smac/DIABLO and survivin in primary meningioma cultures in vivo and in vitro. Expression of Smac/DIABLO, survivin and single-stranded (ss)DNA in vivo were determined immunohistochemically in 100 meningioma surgical specimens, dura and normal human cortex. The expression of the apoptotic enzymes in vitro was analyzed after RNA and protein isolation of all meningiomas via Western blotting and PCR. All examined meningiomas and normal cerebral cortex displayed intense positive cytoplasmic Smac/DIABLO immuno-reactivity. Survivin and ssDNA were expressed in all surgical specimens and showed weak staining overall. Examination of Smac/DIABLO protein via Western blotting showed distinct signals in the cytoplasmic extracts. PCR analysis displayed no changes of Smac/DIABLO and survivin expression in different meningioma grades, normal human cortical cortex or dura. Constant high-level Smac/DIABLO respectively low-level survivin expression in meningiomas and normal brain demonstrate similar apoptotic behavior of meningiomas compared to normal brain tissue. These findings indicate no pathological overexpression of survivin in meningiomas as is evident in several other cancer types impeding apoptosis.
\end{abstract}

Correspondence to: Dr Florian Roser, Department of Neurosurgery, University of Tübingen, Hoppe-Seyler-Str. 3, D-72076 Tübingen, Germany

E-mail: f.roser@gmx.de

Key words: meningioma, apoptosis, Western blotting, PCR, survivin, Smac/DIABLO

\section{Introduction}

Meningiomas constitute one of the most intriguing and challenging tumors of the central nervous system, the definition of malignant potential is beset by the frequent discordance between histology and biologic behavior $(1,2)$. Meningiomas originate from arachnoidal cap cells of the meningeal coverings of the brain, constituting approximatively $13-26 \%$ of all intracranial tumors $(3,4)$. For most of these lesions, the conventional strategy of combining both surgery and radiation therapy for atypical or anaplastic meningiomas provides long-term effective and sufficient clinical results $(5,6)$. However, some meningiomas recur or are resected subtotally due to their delicate location at skullbased structures. Additionally in a minority of patients, regrowth of tumor tissue after irradiation is a major clinical problem. Despite several chemotherapeutic trials, medical interventions in these tumors is unsatisfactory $(7,8)$. The development of novel treatment strategies based on the molecular information has not yet been successfully translated to common clinical practice.

Abnormal apoptosis is a hallmark of human tumors and deregulation of the genes controlling the apoptotic cascade is closely related to tumor development, progression and recurrence (9). Among the many known regulators and effectors of apoptosis, the caspase family as well as survivin and opponent proteins play an important role in the execution phases of apoptosis $(10,11)$. The function of survivin as a member of the family of inhibitors of apoptosis protein (IAP) has been explained by its ability to block the terminal effector cell-death proteases, caspase- 3 and -7 . In addition, high levels of survivin prevent cells from responding to apoptotic stimuli, such as serum deprivation and administration of the anticancer drug etoposide $(12,13)$. However, the inhibitory action of survivin in caspase-3 activity has been debated (14).

Suppressing the activity of the IAPs themselves has been attributed to Smac [second mitochondrial activator of caspases; known as DIABLO (direct IAP binding protein with low pI) in mouse], a nuclear encoded, mitochondrially localized protein, which is released into the cytosol in response to apoptotic stimuli that disrupt the integrity of the mitochondria (15). Smac/DIABLO negatively regulates the caspase inhibitory properties of XIAP (X-linked IAP) by 
Table I. Characteristics of 100 patients with meningioma.

\begin{tabular}{lc}
\hline Characteristics & Range \\
\hline No. of patients & 100 \\
Sex, no. of patients (\%) & \\
$\quad$ Male & $26(26)$ \\
Female & $74(74)$ \\
Age (years) & \\
Mean & 62 \\
Range & $22-85$ \\
WHO grading, no. of patients (\%) & \\
Benign & $66(66)$ \\
Atypical & $30(30)$ \\
Anaplastic & $4(4)$ \\
\hline
\end{tabular}

binding into the same pockets in XIAP which are used to bind caspases; when XIAP binds Smac/DIABLO, the caspases are displaced and primed to affect the execution phase of apoptosis (16).

It is of utmost importance to identify possible key players in this orchestra when aiming for clinical application of new chemotherapeutic agents (17). With this study we provide crucial information on several apoptotic proteins in meningiomas of different WHO grades, as these pro- and antiapoptotic enzymatic complexes in this tumor entity have not been previously studied in detail.

\section{Materials and methods}

Tumor specimens and cell culture. Meningioma surgical specimens were obtained from the Neurosurgical Department in accordance to regulations of the Ethics Committee of the University of Tübingen. Patient data associated with the in vivo and in vitro studies are characterized in Table I. Primary cultures were obtained from tumor tissue samples within $30 \mathrm{~min}$ of surgical removal. Samples were first washed in phosphate-buffered saline (PBS), reduced and mashed through a filter and placed in Dulbecco's modified Eagle's medium (DMEM) with fetal bovine serum (FBS), 2 mmol/1 L-glutamine and $0.1 \% 50 \mathrm{mg} / \mathrm{ml}$ Gentamicin (Invitrogen, Grand Island, NY). Cells were plated in $25-\mathrm{mm}^{2}$ tissue culture flasks and incubated at $37^{\circ} \mathrm{C}$ in a humidified atmosphere of $5 \% \mathrm{CO}_{2}$. Medium was changed every 3-4 days and cultures were split using $600 \mu \mathrm{l}$ Accutase (PAA, Pasching; Austria). Viable cells were stored in liquid nitrogen in $90 \%$ medium/ $10 \%$ dimethyl sulfoxide. The malignant meningioma IOMMLee cell line was a kind gift from A. Lal (Department of Neurological Surgery, University of California, San Francisco, CA, USA).

Immunohistochemical staining. Four-micron sections containing human meningiomas were cut from formalinfixed tissue embedded in paraffin blocks. Normal cerebral cortex (Biochain, Inc., Hayward, CA), normal cerebral meninges and tonsil were used as positive controls. Slides containing tissue were deparaffinized by bathing them with a series of Histolene (Engelbrecht, Edermuende, Germany) and alcohol solutions. Vectastain Elite Universal Kits (Vector Laboratories, Burlingame, CA) were used according to the manufacturer's protocol. Briefly, the slides were treated with an antigen unmasking solution (citrate buffer solution $\mathrm{pH}$ 6.0), rinsed with PBS and bathed in a $3 \% \mathrm{H}_{2} \mathrm{O}_{2}$ solution for $10 \mathrm{~min}$, followed by blocking of avidin/biotin (Vector Laboratories). Slides were incubated overnight at $4{ }^{\circ} \mathrm{C}$ with primary Smac/ DIABLO rabbit polyclonal antibody (Ab13817; Abcam, Cambridge, MA) at a dilution of 1:50, survivin rabbit polyclonal antibody (Ab469; Abcam) at a dilution of 1:100, EMA mouse monoclonal antibody (M0613; Dako, Hamburg) at a dilution of 1:100 and vimentin mouse monoclonal antibody (M7020; Dako) at a dilution of 1:200. Following the incubation with the primary antibody and a two-times PBS wash, biotinylated secondary antibody was applied, then incubated with premixed avidin-biotin-peroxide complex (ABC; Vector Laboratories). The final immunohistochemical staining was performed using Vector ${ }^{\circledR}$ Novared (Vector Laboratories) to obtain a reaction to the $\mathrm{ABC}$. Sections were counterstained with hematoxylin and examined by light microscopic studies.

For immunohistochemical staining of ssDNA the deparaffinized slides were treated with $0.15 \mathrm{mg} / \mathrm{ml}$ saponin and $20 \mu \mathrm{g} / \mathrm{ml}$ proteinase $\mathrm{K}$ in PBS for $20 \mathrm{~min}$. A three-time PBS wash was followed by an incubation with $50 \%$ formamide for $20 \mathrm{~min}$ at $60^{\circ} \mathrm{C}$. After a $5 \mathrm{~min}$ wash in icecold PBS the slides were blocked with $3 \% \mathrm{H}_{2} \mathrm{O}_{2}$ solution for 5 and 15 min with $3 \%$ non-fat dry milk. Slides were incubated for $15 \mathrm{~min}$ with primary mouse monoclonal antibody ssDNA (ALX-804-192; Alexis, San Diego, CA) at a dilution of $1: 100$ in $1 \%$ non-fat dry milk. Following the incubation with the primary antibody and a two-time PBS wash, peroxidase-conjugated anti-mouse $\operatorname{IgM}$ secondary antibody (04-6820, Invitrogen, Inc., Carlsbad, CA) were applied for $15 \mathrm{~min}$ at a dilution of 1:100. The immunohistochemical staining was performed as described earlier.

Grading of immunohistochemical staining. The immunohistochemical samples were graded on the basis of a 5-point scoring system demonstrating the percentage of cells that showed positive staining, as previously published (18). The scores were as follows: 0 , no staining noted; $1,<1 \%$ of cells stained; $2,1-10 \%$ of cells stained; $3,11-50 \%$ of cells stained; and $4,>50 \%$ of cells stained.

Immunocytochemical staining. An immunocytochemical analysis was performed on meningioma cells growing in a monolayer fashion in culture. The cells were subjected to treatment, plated in 4-well glass slides, and allowed to remain in growth media for 2-3 days as described earlier. After removal of the growth media, the slides were rinsed with PBS for 5 min followed by fixation for Smac/DIABLO and survivin with 4\% PFA pH 7.0 in PBS for $15 \mathrm{~min}$ at room temperature. The slides were rinsed two-times with PBS and the PFA treated cells were incubated with $3 \%$ Triton-X 100 in PBS for $10 \mathrm{~min}$. All cells were blocked with $10 \%$ goat serum in PBS for $30 \mathrm{~min}$ at room temperature. Slides were incubated $1 \mathrm{~h}$ at $37^{\circ} \mathrm{C}$ with following primary antibodies: 


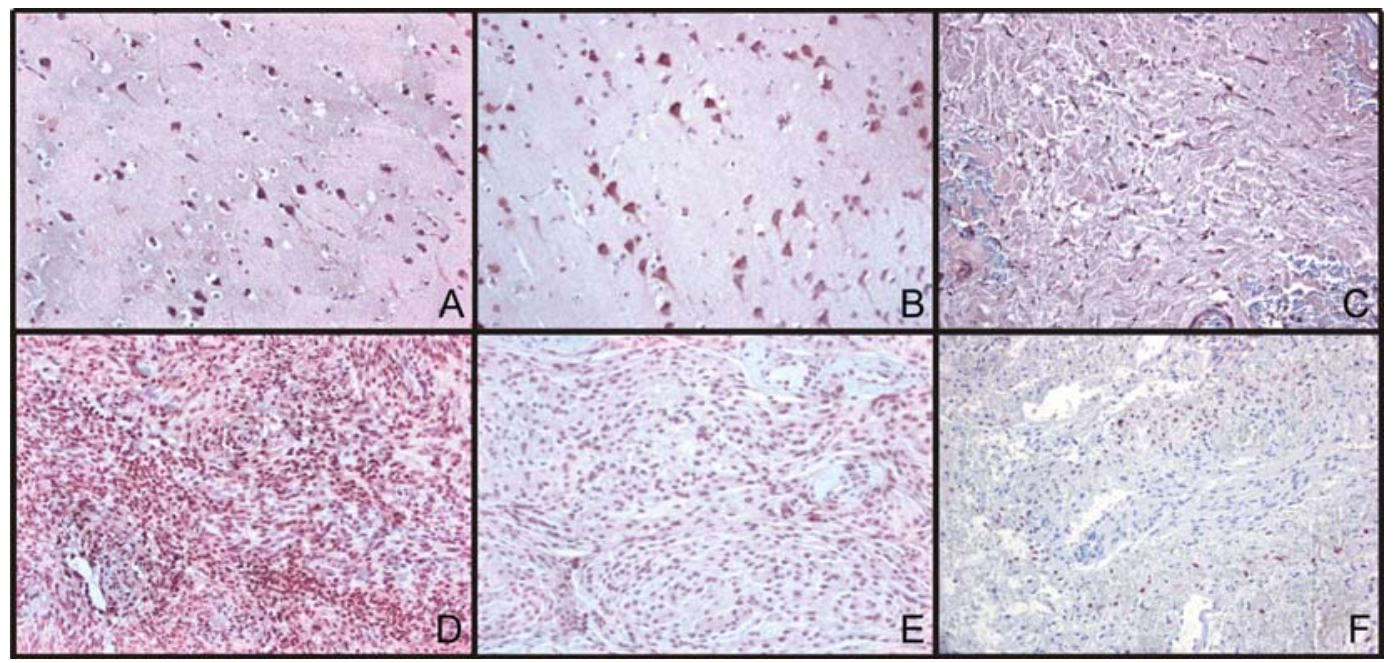

Figure 1. Photomicrographs demonstrating expression of apoptotic enzymes. Positive immunoreactivity appears as red staining (Vector ${ }^{\circledR}$ NovaRed ${ }^{\mathrm{TM}}$ ). Strong Smac/DIABLO immunoreactivity is seen in the cytoplasm of the neurons in normal brain (A) and in the cytoplasma of meningiomas (D). Survivin displayed a weak cytoplasmic and nuclear staining in normal brain (B) and meningiomas (E). Detection of ssDNA (F7-26) as positive apoptosis marker in cerebral meninges $(\mathrm{C})$ and meningioma $(\mathrm{F})$. Original magnification $\mathrm{x} 10$.

Smac/DIABLO rabbit polyclonal antibody (Ab13817; Abcam) at a dilution of $1: 25$, survivin rabbit polyclonal antibody (Ab469; Abcam) at a dilution of 1:50, EMA mouse monoclonal antibody (M0613; Dako) at a dilution of 1:100 and Vimentin mouse monoclonal antibody (M7020; Dako) at a dilution of 1:200. After a three-time wash with PBS, addition of the secondary fluorescence antibody Alexa Fluor 488 goat (1:200, Invitrogen, Inc.) for $1 \mathrm{~h}$ at room temperature in the dark. Finally after a two-time wash with PBS the slides were mounted with DAPI-containing fluorecence mounting medium.

Protein and ribonucleic acid isolation. Cytoplasmic and nuclear protein and ribonucleic acid (RNA) were isolated from the surgical specimens and primary cell cultures using Paris ${ }^{\circledR}$ kit (Ambion, Inc., Austin, TX), according to the manufacturer's protocol. The nuclear and cytoplasmic protein and RNA was measured spectrophotometrically. The probes were stored at $-80^{\circ} \mathrm{C}$ until use.

Reverse transcription and polymerase chain reaction. RNA samples were DNase treated using the DNA-free kit (Ambion, Inc.) prior to the RT-PCR analysis. Cytoplasmic and nuclear RNA $(0.4 \mu \mathrm{g})$ were reverse-transcribed using random hexamer primers and Transcriptor First Strand cDNA-Synthesis kit (Roche, Mannheim, Germany), according to the manufacturer's protocol. PCR reaction was performed with $50 \mathrm{ng}$ of cDNA in $50 \mu 1$ reaction mixture containing FastStart Taq DNA Polymerase dNTPack (Roche), according to the manufacturer's protocol, with Smac/DIABLO, survivin and ACTB primer (loading control) (SuperArray, Frederick, MD). The PCR conditions were $95^{\circ} \mathrm{C}$ for $15 \mathrm{~min}, 40$ cycles of $95^{\circ} \mathrm{C}$ for $30 \mathrm{sec}$, $55^{\circ} \mathrm{C}$ for $30 \mathrm{sec}$ and $72^{\circ} \mathrm{C}$ for $30 \mathrm{sec}$, and 1 cycle of $72^{\circ} \mathrm{C}$ for $10 \mathrm{~min}$. PCR products $(16 \mu \mathrm{l})$ were subjected to electrophoresis on $10 \%$ TBE-Gel and were stained with SilverQuest ${ }^{\circledR}$ Silver Staining Kit (Nr. LC6070, Invitrogen, Inc.). The intensity of expression for each reaction was analyzed by use of a semiquantitative grading system: Grade 0, no expression; Grade 1, minimal expression; Grade 2, moderate expression; Grade 3, marked expression; and Grade 4, strong expression.
Western blot analysis. Equal amounts of protein $(\sim 100 \mu \mathrm{g})$ were resolved using sodium dodecyl sulfate-polyacrylamide gel electrophoresis (Nupage ${ }^{\circledR}$ Bis-Tris-Gel 4-12\%; Invitrogen, Inc.) and transferred to polyvinylidene difluoride Hybond-P membrane (Invitrogen, Inc.). The membrane was blocked and probed using a Smac/DIABLO rabbit polyclonal antibody (AF789; R\&D Systems, Minneapolis, MN) at a dilution of 1:2,000. An antibody against $\beta$-actin $(1: 1,000$; Ab8226, Abcam, Cambridge, UK) was used to confirm equal loading among the samples. The Western blots were visualized using Western Breeze ${ }^{\circledR}$ Chromogenic Kit (Invitrogen, Inc.). The intensity of expression for each reaction was analyzed by use of a semi-quantitative grading system: Grade 0 , no expression; Grade 1, minimal expression; Grade 2, moderate expression; Grade 3, marked expression; and Grade 4, strong expression.

Statistical analysis. Results are expressed as mean \pm SEM. Statistical analysis was performed using an unpaired t-test. $\mathrm{P}$-values $<0.05$ were considered statistically significant.

\section{Results}

Patient demographics and tumor characteristics. Of the 100 patients studied, $74 \%$ were women and the patients ranged in age from 22 to 85 years with a median of 62 years (Table I). Most tumors were histologically benign; there were 30 atypical and 4 anaplastic meningiomas. For in vitro immunocytochemical staining studies, seven primary cell cultures were grown in monolayer cultures. The primary cell cultures were immunocytochemically stained with EMA and vimentin antibodies to verify presence of the meningioma tumor cells.

Immunohistochemical analysis of apoptosis enzymes in meningiomas. Immunohistochemical staining for Smac/ DIABLO was performed on 100 human meningioma surgical specimens and tonsil tissue as positive control. All hundred meningiomas stained positively for Smac/DIABLO (Fig. 1D). The Smac/DIABLO immunoreactivity was found exclusively in the cytoplasm of all meningiomas studied. In fact, 61 
Table II. Immunoreactivity grades of 100 human meningiomas immunohistochemically stained for Smac/DIABLO (\%).

\begin{tabular}{|c|c|c|c|c|c|c|}
\hline \multirow[b]{2}{*}{ WHO } & \multicolumn{5}{|c|}{ Staining grade } & \multirow[b]{2}{*}{ Total } \\
\hline & 0 & 1 & 2 & 3 & 4 & \\
\hline Benign & $0(0)$ & $1(1)$ & $4 \quad(6)$ & $30(46)$ & $31(47)$ & $66 \quad(66)$ \\
\hline Atypical & $0(0)$ & $0(0)$ & $8(27)$ & $12(40)$ & $10(33)$ & $30 \quad(30)$ \\
\hline Malignant & $0(0)$ & $0(0)$ & $0 \quad(0)$ & $2(50)$ & $2(50)$ & $4 \quad(4)$ \\
\hline Total & $0(0)$ & $1(1)$ & $12(12)$ & $44(44)$ & $43(43)$ & $100(100)$ \\
\hline
\end{tabular}

Table III. Immunoreactivity grades of 100 human meningiomas immunohistochemically stained for survivin (\%).

\begin{tabular}{lcrrrrr}
\hline & \multicolumn{5}{c}{ Staining grade } & \\
\cline { 2 - 5 } WHO & 0 & 1 & 2 & 3 & \multirow{2}{*}{ Total } \\
\hline Benign & $0(0)$ & $28(43)$ & $24(36)$ & $14(21)$ & $0(0)$ & $66(66)$ \\
Atypical & $0(0)$ & $18(60)$ & $6(20)$ & $6(20)$ & $0(0)$ & $30(30)$ \\
Malignant & $0(0)$ & $1(25)$ & $1(25)$ & $2(50)$ & $0(0)$ & 4 \\
Total & $0(0)$ & $47(47)$ & $31(31)$ & $22(22)$ & $0(0)$ & $100(100)$ \\
\hline
\end{tabular}

Table IV. Immunoreactivity grades of 100 human meningiomas immunohistochemically stained for ssDNA (\%).

\begin{tabular}{lrrrrrr}
\hline & \multicolumn{9}{c}{ Staining grade } & \\
\cline { 2 - 5 } WHO & 0 & 1 & 2 & 3 & \multirow{2}{*}{ Total } \\
\hline Benign & $2(3)$ & $39(59)$ & $18(27)$ & $6(9)$ & $1(2)$ & $66(66)$ \\
Atypical & $3(17)$ & $20(60)$ & $4(13)$ & $0(0)$ & $1(3)$ & $30(30)$ \\
Malignant & $0(0)$ & $2(50)$ & $2(50)$ & $0(0)$ & $0(0)$ & 4 \\
Total & $7(7)$ & $61(61)$ & $24(24)$ & $6(6)$ & $2(2)$ & $100(100)$ \\
\hline
\end{tabular}

(93\%) of the 66 benign meningiomas and $22(73 \%)$ of the 30 atypical meningiomas exhibited Grade 3 or 4 staining (Table II). Only seven benign meningiomas (7\%) and eight atypical tumors (27\%) displayed Grade 1 or 2 staining. Normal cerebral cortex stained for Smac/DIABLO displayed strong (Grade 4) staining of the cytoplasma (Fig. 1A).

The same tumors were examined for survivin and all displayed positive staining (Fig. 1E). Survivin immunoreactivity was found often in cytoplasm, sometimes in cytoplasm and nucleus and only rarely in the nucleus. In contrast to Smac/DIABLO no specimen displayed Grade 4 staining. Most of the benign meningiomas $52(79 \%)$ and 24 atypical tumors $(80 \%)$ exhibited Grade 1 or 2 staining (Table III). Fourteen $(21 \%)$ of the 66 benign meningiomas and $6(20 \%)$ of the 30 atypical meningiomas exhibited Grade 3 staining.

To verify the degree of apoptosis in meningiomas ssDNA was analyzed in the 100 specimens. Most meningiomas displayed a small amount of ssDNA. Forty-one benign $(62 \%)$ and 22 atypical $(77 \%)$ meningiomas showed no or almost no occurance of ssDNA (Table IV).

Immunocytochemical analysis of apotosis enzymes in meningiomas. The immunocytochemical analysis for Smac/ DIABLO and survivin was performed on the IOMM-Lee malignant meningioma cell line and on six benign/atypical meningiomas grown in cell culture. All seven specimens exhibited extensive (Grade 4) cytoplasmatic staining of Smac/DIABLO (Fig. 2A, B, D and E), whereas cells stained with survivin displayed moderate colouring of the cytoplasm and sometimes of the nucleus (Grade 2) (Fig. 2C and F).

Expression of the Smac/DIABLO protein in meningiomas. One hundred meningioma primary cell cultures, the IOMMLee cell line, normal cerbral cortex and two surgical specimens of human dura were processed for Western blot experiments. Cytoplasmic and nuclear protein extracts were 

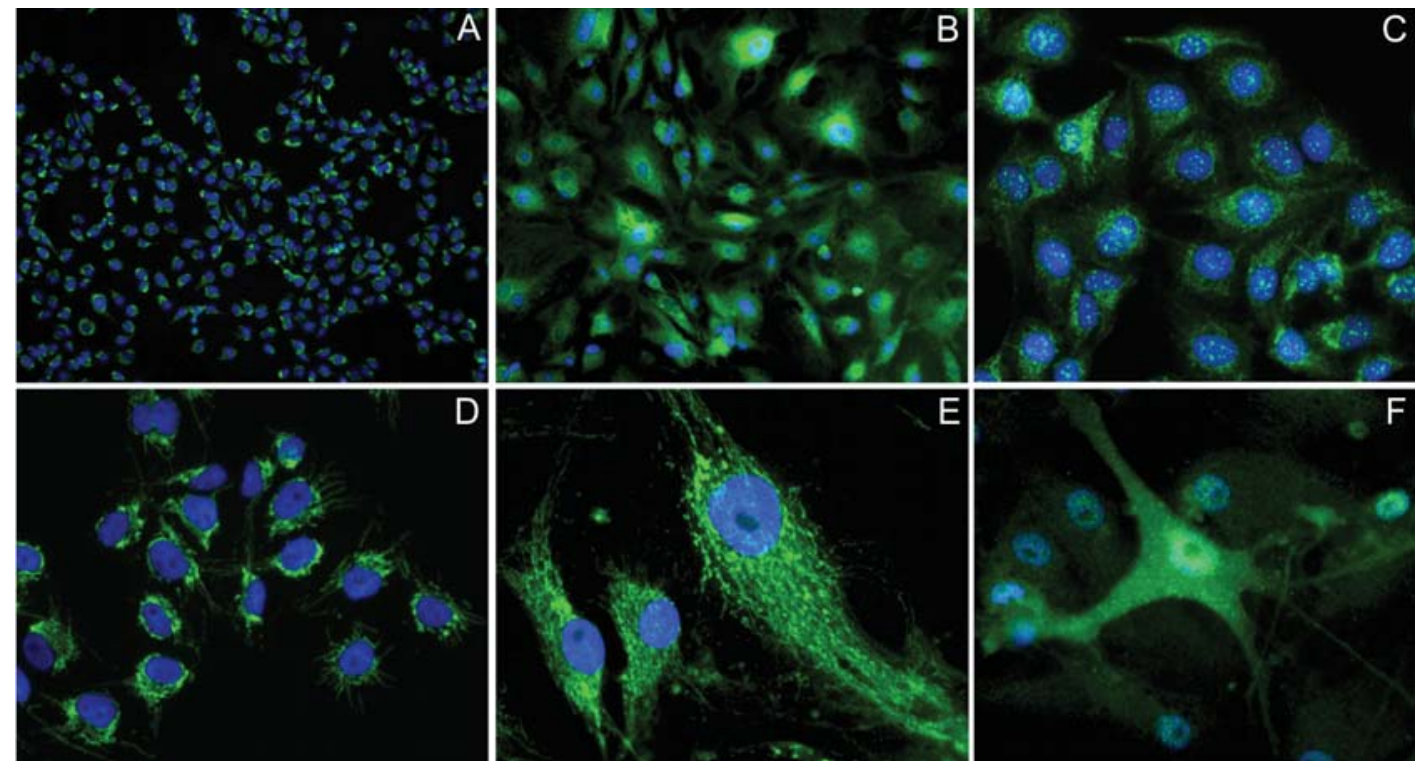

Figure 2. Expression of Smac/DIABLO in meningioma primary cell culture. Positive immunoreactivity appears as green staining (Alexa Fluor 488). Strong Smac/DIABLO immunoreactivity is seen in the cytoplasm of the IOMM-Lee cell line [(A), x10; (D), x40], and meningioma [(B), x10; (E), x40]. In contrast survivin displayed a weak cytoplasmic and sometimes nuclear staining in IOMM-Lee cell line (C) and meningioma (F). Original magnification x40 except for (A) and (B).

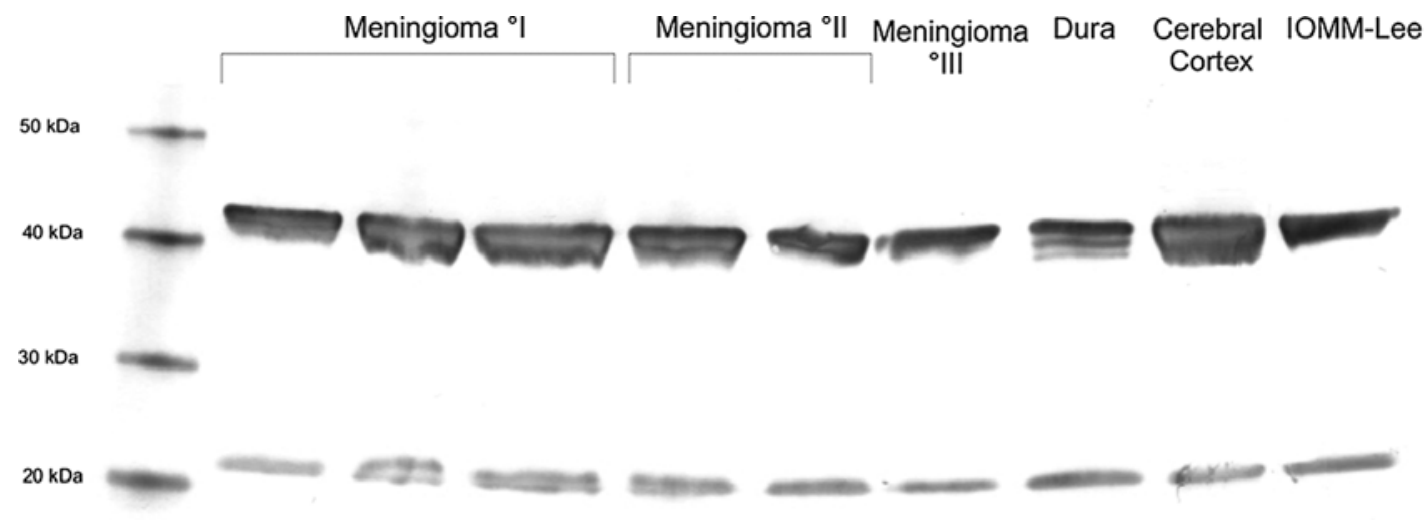

Figure 3. Western blot of Smac/DIABLO in meningiomas, IOMM-Lee cell line, normal cerebral cortex and human dura. Smac/DIABLO displayed a band at $\sim 21 \mathrm{kDa}$ in the cytoplasmic extracts and a large band at $42 \mathrm{kDa}$ for $\beta$-actin, which was used to confirm equal loading among samples. The mean values were determined by semi-quantitative analysis.

isolated. Smac/ DIABLO has a molecular weight of $\sim 27 \mathrm{kDa}$ and the loading control $\mathrm{B}$-actin $42 \mathrm{kDa}$. All meningiomas samples exhibited strong staining of a band at $\sim 21 \mathrm{kDa}$ in the cytoplasmic extracts for Smac/DIABLO and a large band at $42 \mathrm{kDa}$ for the loading control B-actin (Fig. 3). The nuclear protein extracts showed no staining for Smac/DIABLO as expected by cytoplasmic localization of the proteins.

Expression of apoptosis enzyme RNA in meningiomas. Expression of RNA was determined in 100 meningioma primary cell cultures, the IOMM-Lee cell line, normal cerebral cortex and three dura surgical specimens by reversetranscriptase PCR analysis. PCR products of Smac/DIABLO and survivin were 118 and $73 \mathrm{bp}$, respectively. The product of the loading control ACTB was $183 \mathrm{bp}$. Smac/DIABLO showed a constant high-level expression in meningiomas, IOMM-Lee cell line, cerebral cortex and dura, in contrast to survivin, which was expressed throughout the specimens at a low-level. No changes in the expression of survivin with increasing WHO grade, in IOMM-Lee cell line, dura and cerebral cortex were seen (Fig. 4).

\section{Discussion}

Meningiomas are the most frequent tumors of the central nervous system. Although generally slow growing, they continue to be a major cause of morbidity and mortality due to recurrence and unresponsiveness to adjuvant therapies. The finding that apoptotic enzymes are expressed in meningiomas is fundamental and might create potential therapeutic opportunities. To identify the role of apoptosis in meningioma cell death regulation, we investigated macromolecular (RNA and protein) synthesis and activity in meningiomas of different malignancies.

A feature common to all successful multicellular organisms is the ability to control the cell number. This property is 


\section{Expression of SMAC/Diablo and Survivin in untreated Meningiomas in vitro}

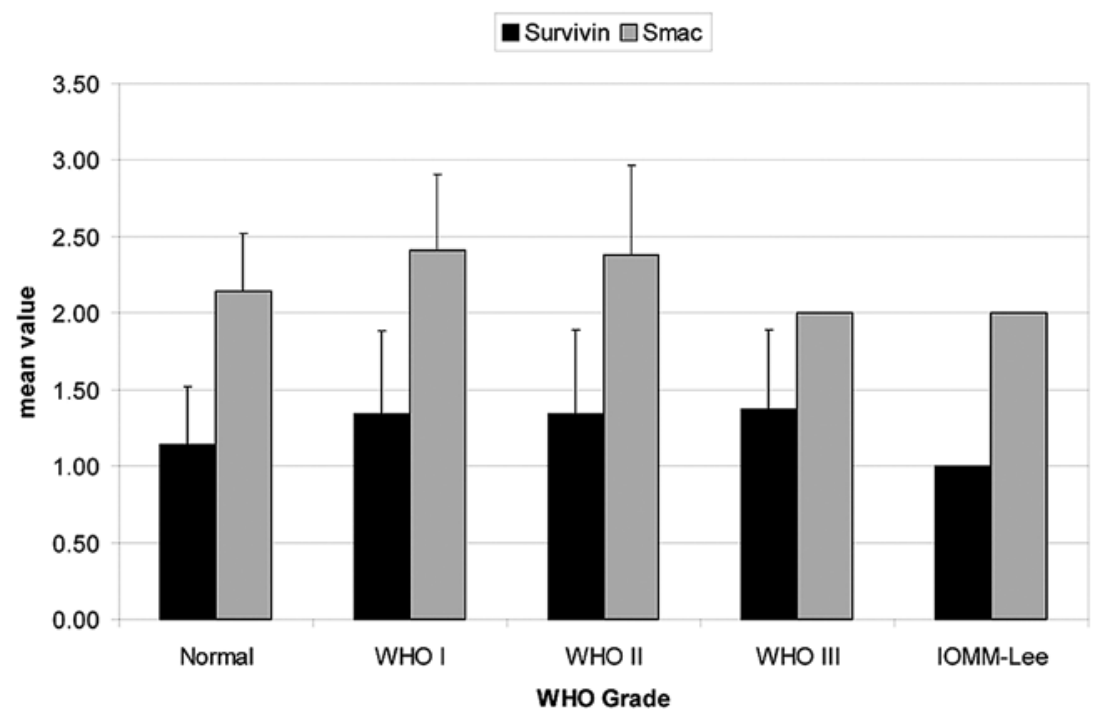

Figure 4. PCR analysis of Smac/DIABLO and survivin in meningiomas, IOMM-Lee cell line and normal cerebral cortex. Mean values where determined by semi-quantitative analysis. B-actin was used to confirm equal loading among samples.

essential in developmental and adult phases, and is achieved by modulating both cellular birth and death (19). The latter event is largely affected through the activation of a strongly regulated series of events that lead to deconstruction, death and ultimately removal of the cell in a process known as apoptosis.

Survivin expression. Survivin is known to be expressed in fetal tissue and transformed cells in adults $(20,21)$. It is expressed in most common human cancers of the lung, colon, pancreas, prostate, breast, esophagus, liver, stomach, uterus, bladder and skin, as well as in neuroblastomas and melanomas (21-27). The expression of survivin not only appears to correlate with aggressive tumor behavior and poor prognosis, but is also considered a risk factor for resistance to chemotherapy and radiation treatment (28). In the majority of primary nervous system tumors, particularly in glioblastomas and peripheral nerve sheath tumors survivin is also expressed (29). In glioblastomas, positive survivin expression was seen in immunohistochemistry and detected in high levels throughout the specimens, with a positive correlation to the Ki-67 proliferation index $(30,31)$. However, no correlation between the intensity of survivin staining and the clinical course of the tumors has been seen (29). Moreover, simultaneous expression of survivin in both nucleus and cytoplasm has been interpreted as an important prognostic factor in astrocytoma (32).

Somewhat contrary results have been demonstrated regarding survivin expression in meningiomas: with immunoblotting techniques a high level of survivin protein has been shown (33), whereas flow cytometrical analysis showed that both spontaneous and radiation-induced apoptosis levels are very low in these neoplasms (34). Das et al found in benign meningiomas a survivin expression in $94 \%(85 / 90)$ of tissue samples and no correlation of expression with Bax/ $\mathrm{Bcl} 2$ or clinicopathological factors (35). Kayaselcuk et al correlated survivin expression to recurrence by means of immunohistochemistry staining in 40 meningiomas. Although no or only mild expression in high grade meningiomas has been noted, there was a significant relation between grade 1 and expression of survivin and Ki-67 (36).

Combining in vitro and in vivo experiments we provide evidence of a low level expression throughout all grades of meningiomas, with no increase in meningiomas with a high cell turnover. The expression of survivin in benign slow growing tumors does not provide evidence that this antiapoptotic protein might be related to tumor malignancy and poor prognosis in meningiomas. The suggested overexpression of survivin as an early event in the stepwise tumorigenesis and its responsibility for the growth advantage during tumorigenic progression can only be applied to malignant meningiomas (33). However, investigating the malignant IOMM-Lee cell line we suggest that these cells do not express typical features of a meningioma cell line.

Mediating survivin activity, either as a mitosis regulator and apoptosis inhibitor should be taken into account in therapeutic strategies using survivin (31). In an animal model, the topoisomerase-I-inhibitor irinotecan led to decrease in tumor growth in malignant menignioma that was accompanied by a decrease in Bcl-2 and survivin levels and an increase in apoptotic cell death. However, the treatment was much more effective against the IOMM-Lee cell line than against primary meningioma cultures. This focuses its treatment options to atypical or malignant meningiomas and should be evaluated further for this purpose (37).

ssDNA was stained in vivo to verify the amount of apoptosis in meningiomas, as the antibody only stains singlestranded apoptotic DNA but not necrotic cells (38-40), however no significant inverse correlation with Smac/ DIABLO or surviving expression has been seen as previously shown in glioblastomas as well $(31,41)$. 
Smac/DIABLO expression. The functions of activated caspases are inhibited by the binding of inhibitors of apoptosis (IAPs). The function of IAPs is regulated by pro-apoptotic protein Second Mitochondria-Derived Activator of Caspases (Smac) or Direct IAP Binding Protein with low isoelectric point, pI (DIABLO). Induction of apoptosis leads to increased mitochondrial permeability to Smac/DIABLO, which adheres to IAPs inhibiting their caspase-binding activity. The role of Smac/DIABLO, therefore, may have significant diagnostic and therapeutic features in carcinogenesis (42). Tumor cells with reduced Smac resist apoptosis leading to the suggestion for an obligatory role for Smac/DIABLO in these tumor cells during several pathways of apoptosis induction (43). It has been shown to induce apoptosis in various types of cancer, including ovarian (44), renal cell (45), colon (42), bladder (46) and lung (47).

The presence of apoptosis initiating proteins in cells of the central nervous system have been verified in mammalian stroke studies (48-51). One report describes an inhibition of clonogenic tumor growth by Smac through blocking proliferation and enhancing apoptosis in a cell type-dependent manner in neuroblastoma cells (52). This is the first study detailing the findings of Smac/DIABLO in benign, atypical and anaplastic meningioma cells.

As demonstrated in renal cell carcinoma (53) mRNA expression levels of Smac/DIABLO in meningioma cells did not relate to tumor stage or grade, although Smac/DIABLO is expressed at a high level. The lower expression of Smac/ DIABLO displayed in WHO grade III meningiomas did not appear in Western blotting or immunohistochemistry. This might be bias due to the small numbers of WHO III tissue samples in this series. The semi-quantitative derived mean value of survivin was significant lower than Smac/DIABLO (t-test, $\mathrm{P}<0.01)$.

Considering therapeutic options for treatment-resistant meningiomas synthetic Smac/DIABLO peptides have shown an enhancing effect of etoposide-induced apoptosis in human glioblastoma cell lines (54). This was also shown with various chemotherapeutic drugs and irradiation treated breast cancer cells, who either were overexpressed with the Smac/DIABLO gene or were treated with Smac/DIABLO peptide (55). Furthermore, Smac/DIABLO is able to stimulate induced apoptosis by promoting caspase- 3 activation and cytochrome-c release in colon cancer cells (56) or via an escalation of inhibition of the Survivin/Smac-DIABLO interaction (57). Therefore it would be worthwhile to test this marker as a target for chemotherapeutic agents.

Verifying constant high-level Smac/DIABLO, respectively low-level survivin expression in meningiomas this study indicates that these apoptotic players might be beneficial as targets for adjuvant therapeutic strategies in recurrent atypical meningiomas, although no pathological overexpression of survivin was observed as in several other types of cancer impeding apoptosis.

\section{Acknowledgements}

We are grateful to Anita Lal (UCSF, CA, USA) for kindly providing the IOMM-Lee cell line.

\section{References}

1. Mahmood A, Caccamo DV, Tomecek FJ and Malik GM: Atypical and malignant meningiomas: a clinicopathological review. Neurosurgery 33: 955-963, 1993.

2. Schittenhelm J, Mittelbronn M, Roser F, Tatagiba M, Mawrin C and Bornemann A: Patterns of SPARC expression and basement membrane intactness at the tumour-brain border of invasive meningiomas. Neuropathol Appl Neurobiol 32: 525-531, 2006.

3. Kleihues P, Louis DN, Scheithauer BW, et al: The WHO classification of tumors of the nervous system. J Neuropathol Exp Neurol 61: 215-226, 2002.

4. Riemenschneider MJ, Perry A and Reifenberger G: Histological classification and molecular genetics of meningiomas. Lancet Neurol 5: 1045-1054, 2006.

5. McMullen KP and Stieber VW: Meningioma: current treatment options and future directions. Curr Treat Options Oncol 5: 499-509, 2004

6. Whittle IR, Smith C, Navoo P and Collie D: Meningiomas. Lancet 363: 1535-1543, 2004.

7. Kyritsis AP: Chemotherapy for meningiomas. J Neurooncol 29: 269-272, 1996.

8. Newton HB, Slivka MA and Stevens C: Hydroxyurea chemotherapy for unresectable or residual meningioma. J Neurooncol 49: 165-170, 2001.

9. Williams GT: Programmed cell death: apoptosis and oncogenesis. Cell 65: 1097-1098, 1991.

10. Vakkala M, Paakko P and Soini Y: Expression of caspases 3, 6 and 8 is increased in parallel with apoptosis and histological aggressiveness of the breast lesion. Br J Cancer 81: 592-599, 1999.

11. Donoghue S, Baden HS, Lauder I, Sobolewski S and Pringle JH: Immunohistochemical localization of caspase-3 correlates with clinical outcome in B-cell diffuse large-cell lymphoma. Cancer Res 59: 5386-5391, 1999.

12. Shin S, Sung BJ, Cho YS, et al: An anti-apoptotic protein human survivin is a direct inhibitor of caspase-3 and -7 . Biochemistry 40: 1117-1123, 2001.

13. Tamm I, Wang Y, Sausville E, et al: IAP-family protein survivin inhibits caspase activity and apoptosis induced by Fas (CD95), Bax, caspases, and anticancer drugs. Cancer Res 58: 5315-5320, 1998.

14. Banks DP, Plescia J, Altieri DC, et al: Survivin does not inhibit caspase-3 activity. Blood 96: 4002-4003, 2000.

15. Du C, Fang M, Li Y, Li L and Wang X: Smac, a mitochondrial protein that promotes cytochrome c-dependent caspase activation by eliminating IAP inhibition. Cell 102: 33-42, 2000.

16. Verhagen AM and Vaux DL: Cell death regulation by the mammalian IAP antagonist Diablo/Smac. Apoptosis 7: 163-166, 2002.

17. Pfister C, Ritz R, Pfrommer H, Bornemann A, Tatagiba MS and Roser F: Are there attacking points in the eicosanoid cascade for chemotherapeutic options in benign meningiomas? Neurosurg Focus 23: E8, 2007.

18. Ragel BT, Jensen RL, Gillespie DL, Prescott SM and Couldwell WT: Ubiquitous expression of cyclooxygenase-2 in meningiomas and decrease in cell growth following in vitro treatment with the inhibitor celecoxib: potential therapeutic application. J Neurosurg 103: 508-517, 2005.

19. Vaux DL and Korsmeyer SJ: Cell death in development. Cell 96: 245-254, 1999.

20. Adida C, Berrebi D, Peuchmaur M, Reyes-Mugica M and Altieri DC: Anti-apoptosis gene, survivin, and prognosis of neuroblastoma. Lancet 351: 882-883, 1998.

21. Ambrosini G, Adida C, Sirugo G and Altieri DC: Induction of apoptosis and inhibition of cell proliferation by survivin gene targeting. J Biol Chem 273: 11177-11182, 1998.

22. Adida C, Crotty PL, McGrath J, Berrebi D, Diebold J and Altieri DC: Developmentally regulated expression of the novel cancer anti-apoptosis gene survivin in human and mouse differentiation. Am J Pathol 152: 43-49, 1998.

23. Grossman D, McNiff JM, Li F and Altieri DC: Expression of the apoptosis inhibitor, survivin, in non-melanoma skin cancer and gene targeting in a keratinocyte cell line. Lab Invest 79: 1121-1126, 1999

24. Ito T, Shiraki K, Sugimoto K, et al: Survivin promotes cell proliferation in human hepatocellular carcinoma. Hepatology 31: 1080-1085, 2000. 
25. Lu CD, Altieri DC and Tanigawa N: Expression of a novel antiapoptosis gene, survivin, correlated with tumor cell apoptosis and p53 accumulation in gastric carcinomas. Cancer Res 58: 1808-1812, 1998.

26. Monzo M, Rosell R, Felip E, et al: A novel anti-apoptosis gene: re-expression of survivin messenger RNA as a prognosis marker in non-small-cell lung cancers. J Clin Oncol 17: 2100-2104, 1999.

27. Swana HS, Grossman D, Anthony JN, Weiss RM and Altieri DC: Tumor content of the antiapoptosis molecule survivin and recurrence of bladder cancer. N Engl J Med 341: 452-453, 1999.

28. Asanuma K, Moriai R, Yajima $\mathrm{T}$, et al: Survivin as a radioresistance factor in pancreatic cancer. Jpn J Cancer Res 91: 1204-1209, 2000.

29. Sasaki T, Lopes MB, Hankins GR and Helm GA: Expression of survivin, an inhibitor of apoptosis protein, in tumors of the nervous system. Acta Neuropathol 104: 105-109, 2002.

30. Angileri FF, Aguennouz M, Conti A, et al: Nuclear factorkappaB activation and differential expression of survivin and Bcl-2 in human grade 2-4 astrocytomas. Cancer 112: 2258-2266, 2008.

31. Mellai M, Caldera V, Patrucco A, Annovazzi L and Schiffer D: Survivin expression in glioblastomas correlates with proliferation, but not with apoptosis. Anticancer Res 28: 109-118, 2008.

32. Saito T, Arifin MT, Hama S, et al: Survivin subcellular localization in high-grade astrocytomas: simultaneous expression in both nucleus and cytoplasm is negative prognostic marker. J Neurooncol 82: 193-198, 2007.

33. Al-Khalaf HH, Lach B, Allam A, et al: Expression of survivin and $\mathrm{p} 16(\mathrm{INK} 4 \mathrm{a}) / \mathrm{Cdk} 6 / \mathrm{pRB}$ proteins and induction of apoptosis in response to radiation and cisplatin in meningioma cells. Brain Res 1188: 25-34, 2008.

34. Hassounah M, Lach B, Allam A, et al: Benign tumors from the human nervous system express high levels of survivin and are resistant to spontaneous and radiation-induced apoptosis. J Neurooncol 72: 203-208, 2005.

35. Das A, Tan WL and Smith DR: Expression of the inhibitor of apoptosis protein survivin in benign meningiomas. Cancer Lett 193: 217-223, 2003

36. Kayaselcuk F, Zorludemir S, Bal N, Erdogan B, Erdogan S and Erman T: The expression of survivin and $\mathrm{Ki}-67$ in meningiomas: correlation with grade and clinical outcome. J Neurooncol 67: 209-214, 2004.

37. Gupta V, Su YS, Samuelson CG, et al: Irinotecan: a potential new chemotherapeutic agent for atypical or malignant meningiomas. J Neurosurg 106: 455-462, 2007.

38. Ito Y, Shibata MA, Kusakabe K and Otsuki Y: Method of specific detection of apoptosis using formamide-induced DNA denaturation assay. J Histochem Cytochem 54: 683-692, 2006.

39. Korkolopoulou PA, Konstantinidou AE, Patsouris ES, Christodoulou PN, Thomas-Tsagli EA and Davaris PS: Detection of apoptotic cells in archival tissue from diffuse astrocytomas using a monoclonal antibody to single-stranded DNA. J Pathol 193: $377-382,2001$.

40. Zhao J, Schmid-Kotsas A, Gross HJ, Gruenert A and Bachem MG: Sensitivity and specificity of different staining methods to monitor apoptosis induced by oxidative stress in adherent cells. Chin Med J 116: 1923-1929, 2003.

41. Zhen HN, Zhang X, Hu PZ, et al: Survivin expression and its relation with proliferation, apoptosis, and angiogenesis in brain gliomas. Cancer 104: 2775-2783, 2005.
42. Anguiano-Hernandez YM, Chartier A and Huerta S: Smac/ DIABLO and colon cancer. Anticancer Agents Med Chem 7: 467-473, 2007.

43. Rajalingam K, Oswald M, Gottschalk K and Rudel T: Smac/ DIABLO is required for effector caspase activation during apoptosis in human cells. Apoptosis 12: 1503-1510, 2007.

44. McNeish IA, Bell S, McKay T, Tenev T, Marani M and Lemoine NR: Expression of Smac/DIABLO in ovarian carcinoma cells induces apoptosis via a caspase-9-mediated pathway. Exp Cell Res 286: 186-198, 2003.

45. Yan Y, Mahotka C, Heikaus S, et al: Disturbed balance of expression between XIAP and Smac/DIABLO during tumour progression in renal cell carcinomas. Br J Cancer 91: 1349-1357, 2004.

46. Wang L, Fuqing Z, Zheng L and Tong Q: Smac/DIABLO promotes mitomycin C-induced apoptosis of bladder cancer T24 cells. J Huazhong Univ Sci Technolog Med Sci 26: 317-318, 328,2006

47. Sekimura A, Konishi A, Mizuno K, et al: Expression of Smac/DIABLO is a novel prognostic marker in lung cancer. Oncol Rep 11: 797-802, 2004

48. Hu XL, Olsson T, Johansson IM, Brannstrom T and Wester P: Dynamic changes of the anti- and pro-apoptotic proteins Bcl-w, Bcl-2, and Bax with Smac/Diablo mitochondrial release after photothrombotic ring stroke in rats. Eur J Neurosci 20: 1177-1188, 2004.

49. Saito A, Hayashi T, Okuno S, Ferrand-Drake M and Chan PH: Interaction between XIAP and Smac/DIABLO in the mouse brain after transient focal cerebral ischemia. J Cereb Blood Flow Metab 23: 1010-1019, 2003.

50. Saito A, Hayashi T, Okuno S, Nishi T and Chan PH: Oxidative stress is associated with XIAP and Smac/DIABLO signaling pathways in mouse brains after transient focal cerebral ischemia. Stroke 35: 1443-1448, 2004.

51. Siegelin MD, Kossatz LS, Winckler J and Rami A: Regulation of XIAP and Smac/DIABLO in the rat hippocampus following transient forebrain ischemia. Neurochem Int 46: 41-51, 2005.

52. Vogler M, Giagkousiklidis S, Genze F, Gschwend JE, Debatin KM and Fulda S: Inhibition of clonogenic tumor growth: a novel function of Smac contributing to its antitumor activity. Oncogene 24: 7190-7202, 2005.

53. Kempkensteffen C, Hinz S, Christoph F, et al: Expression levels of the mitochondrial IAP antagonists Smac/DIABLO and Omi/HtrA 2 in clear-cell renal cell carcinomas and their prognostic value. J Cancer Res Clin Oncol 134: 543-550, 2008.

54. Mizukawa K, Kawamura A, Sasayama T, et al: Synthetic Smac peptide enhances the effect of etoposide-induced apoptosis in human glioblastoma cell lines. J Neurooncol 77: 247-255, 2006.

55. Fandy TE, Shankar S and Srivastava RK: Smac/DIABLO enhances the therapeutic potential of chemotherapeutic drugs and irradiation, and sensitizes TRAIL-resistant breast cancer cells. Mol Cancer 7: 60, 2008.

56. Bank A, Wang P, Du C, Yu J and Zhang L: SMAC mimetics sensitize non-steroidal anti-inflammatory drug-induced apoptosis by promoting caspase-3-mediated cytochrome c release. Cancer Res 68: 276-284, 2008.

57. Ogura A, Watanabe Y, Iizuka D, et al: Radiation-induced apoptosis of tumor cells is facilitated by inhibition of the interaction between Survivin and Smac/DIABLO. Cancer Lett 259: 71-81, 2008. 